\title{
Acute villous inflammation in the placenta following intrauterine transfusion
}

\author{
JEAN M. SCOTT AND A. HENDERSON \\ From the Research Department, Glasgow Royal Maternity Hospital
}

SYNOPSIS Infection is well recognized as a complication of intrauterine transfusion. The majority of cases are fortunately mild and consist merely of chorio-amnionitis. The present case, of severe type, resulted from contamination of the donor blood with Acinetobacter calcoaceticus. Spread of infection from foetus to mother has been carefully studied and an entirely new type of lesion in the placenta described. This takes the form of acute villous inflammation with resultant micro-abscess formation beneath the trophoblast layer and eventual rupture into the intervillous space. Attempts at localization are poor.

Though intrauterine transfusion is widely used in the treatment of babies severely affected by erythroblastosis foetalis due to maternal Rhesus isoimmunization, it is not a procedure which is entirely free from risk. According to Queenan (1969) one out of every three patients is liable to go into premature labour and $10 \%$ develop infection. Fortunately the latter is generally mild in nature but occasionally it can be severe. This was true of the present case, where we were able not only to identify the source of infection in the baby but also to relate it to unusual changes in the placenta and so determine the natural spread of the disease through the foeto-placental unit to the mother.

\section{Case History}

The patient had already lost three babies due to Rhesus isoimmunization and in the present pregnancy it was decided to carry out intrauterine transfusion at 28 weeks because amniocentesis readings had shown the bilirubin peak to be rising steeply. Antibiotic coverage in the form of cephaloridine $1 \mathrm{~g}$ bd intramuscularly was commenced on the morning of transfusion and at $3 \mathrm{pm}$ on the same day $75 \mathrm{ml}$ of group $\mathrm{O}$, Rhesus-negative, washed packed cells was introduced into the foetal abdomen without undue difficulty. The foetal heart rate remained satisfactory and the patient was returned to the antenatal ward for observation. On the following morning the foetal heart could not be heard. By evening the patient complained of feeling cold and shivery; her temperature had risen to $40.3^{\circ} \mathrm{C}$ and Received for publication 12 July 1972. she began to vomit. This persisted, necessitating the administration of intravenous fluids. Eventually tenderness developed over the uterus and as the diagnosis was suggestive of intrauterine infection it was decided to deliver her vaginally as soon aso possible. Blood cultures were taken and syntocinon given together with gentamycin tid and cephaloridine four hourly, all administered intravenously. Labour ensued and six hours later the patient had a spontaneous breech delivery of a macerated male child. It was noted that the liquor was not foul smelling. Blood loss amounted to $180 \mathrm{ml}$.

The patient's temperature fell to near normal levels but later signs of general peritonitis began to appear, and on surgical advice a laparotomy was performed. It is not proposed to discuss here the patient's further course and treatment, but in brief it can be said that despite complications and a protracted puerperium, she eventually made a good recovery.

\section{Necropsy Findings in the Foetus}

On the following day, before postmortem examination of the foetus, blood was withdrawn from the abdominal cavity after swabbing the abdomen with $20 \%$ aqueous carbolic acid; part was sent for culture, the rest retained for serological examination and a Kleihauer test. A further sample of blood was taken from the heart at necropsy.

The body was that of a premature, macerated, male child weighing $1.40 \mathrm{~kg}$. The crown-heel and crown-rump lengths were 41 and $25 \mathrm{~cm}$ respectively. The umbilical cord and subcutaneous tissues were 
oedematous. The puncture mark of the intrauterine transfusion was in the midaxillary line below the right costal margin and beneath the lower border of the liver. Some bruising was noted around the site.

The abdomen contained $30 \mathrm{ml}$ of rather thick, treacly blood, which was remarkably red in colour and not foul smelling. Indeed there was nothing in the general appearance to suggest infection. The liver $(60 \mathrm{~g})$ was slightly above average size, pale and autolysed. The spleen $(2 \mathrm{~g})$ was small and autolysed. The other organs, though autolysed, showed no obvious abnormality.

The placenta weighed $440 \mathrm{~g}$ and there was $40 \mathrm{ml}$ of blood lying free in the container. It had no foul smell. The cord was macerated and oedematous; the foetal vessels were empty. To one side of the cord insertion there was a slightly raised area of subchorionic thrombosis, $4 \mathrm{~cm}$ in diameter. Appearances suggestive of early diffuse infarction of the decidual floor were noted. On section the placenta was firmer than usual and relatively pale.

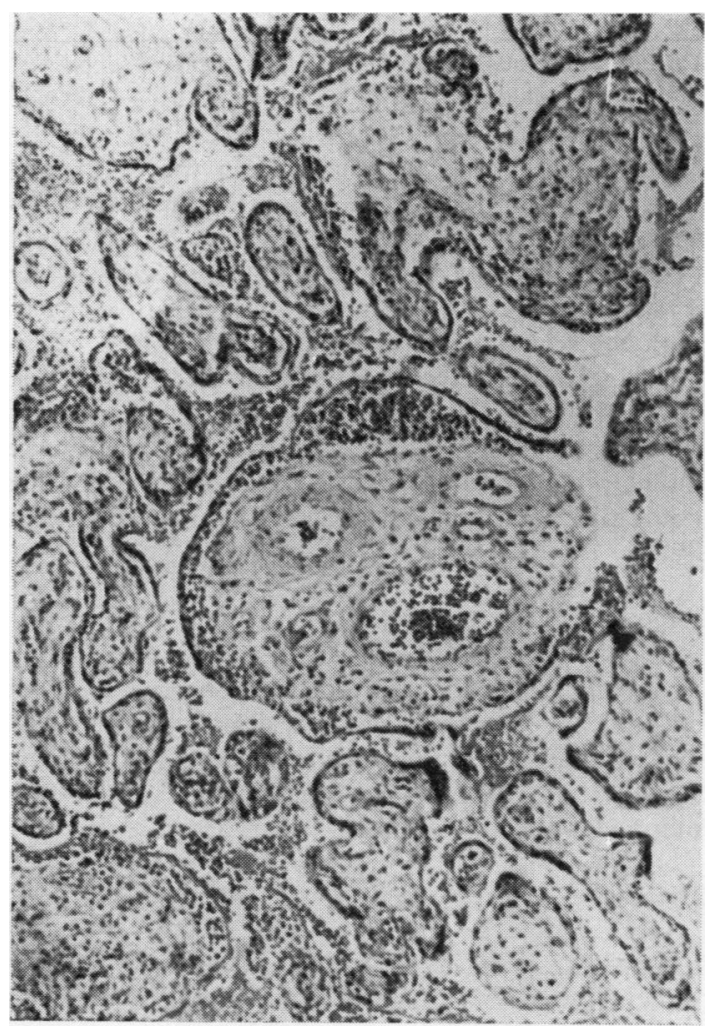

Fig. 1 Villus in the centre shows early type lesion, ie, accumulation of polymorphs beneath trophoblast and micro-abscess formation ( $H \& E \times 62$ ).

\section{Histology}

The lungs showed no evidence of aspiration pneumonia but there was marked desquamation of respiratory epithelium compatible with the degree of autolysis. On the surface of the liver an early focal inflammatory reaction was present in which a few Gram-negative organisms were seen. The liver and the spleen were too autolysed to give any further opinion. Haemorrhage around the needle tract was confirmed and the early cellular reaction here could have been due to the bleeding. No organisms were seen.

The placenta presented an unusual picture. Although the membranes and cord were completely free of any sign of inflammation, the villi were the seat of acute inflammation at various stages. The earliest lesion consisted of small accumulations of inflammatory cells in and around capillaries just beneath the trophoblast. At a later stage small micro-abscesses formed, raising the trophoblast

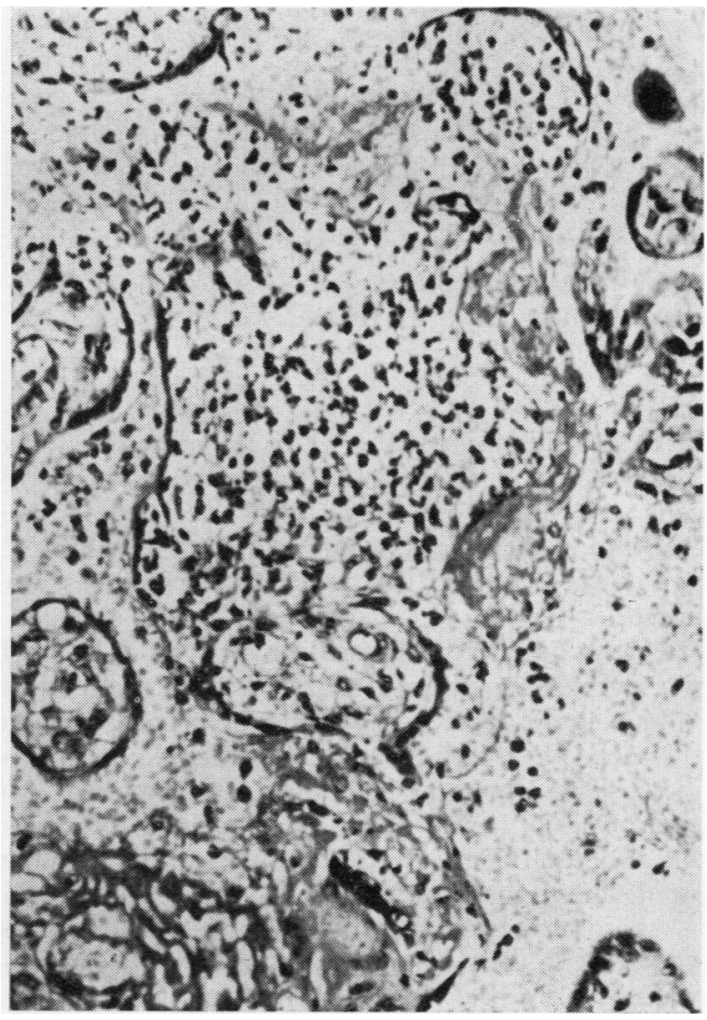

Fig. 2 More developed lesion showing diffuse polymorph infiltration of the villus, degeneration of the trophoblast layer, and rupture $(H \& E \times 155)$. 


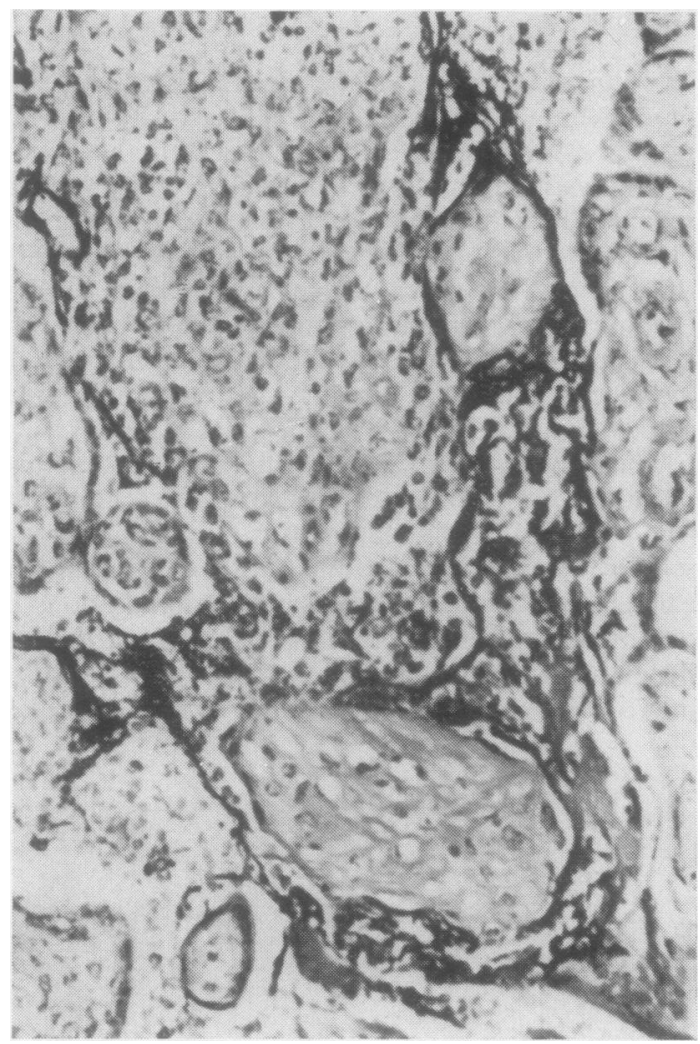

Fig. 3 Attempt at localization. Note fibrin deposition drawing villi together $(P T A H \times 155)$.

layer into small blebs (Fig. 1). In the more developed lesion the whole villus was infiltrated by inflammatory cells and the trophoblast layer was degenerate. Rupture into the intervillous space followed (Fig. 2) and frequently local intervillous thrombosis was noted.

Patchy attempts at localization could be seen where the deposition of fibrin around the affected villus caused adjacent villi to adhere and surround the area (Fig. 3). Elsewhere in the foetal cotyledons, in larger stem branches, and less frequently in anchoring villi (well above their decidual insertion) the fringe capillaries were prominent and occasional small micro-abscesses were seen.

An inflammatory reaction was also noted at the edge of the area of subchorionic thrombosis. This was the only site where the chorionic plate showed involvement and it was obviously due to local spread. Inflammatory change was not marked in the decidua unless by direct spread from a villous lesion. Fibrin deposition was increased and this probably accounted for the naked-eye appearances suggestive of early infarction.

Gram-negative organisms were numerous in all sections of these lesions; in small villous capillaries they were present in large clumps.

\section{Haematology}

The blood bottle was returned to the labour ward store where it lay at room temperature over the weekend before it was sent for bacteriological examination. However, the bottle was sealed and there was less chance of contamination from the air.

Serological investigations and Kleihauer tests were made on blood obtained from the foetal heart and abdomen. The results are shown in Table I. It can

\begin{tabular}{|c|c|c|c|c|c|}
\hline \multirow[t]{2}{*}{ Source } & \multirow[t]{2}{*}{ Group } & \multirow[t]{2}{*}{ Rhesus } & \multicolumn{2}{|l|}{ Test } & \multirow{2}{*}{$\begin{array}{l}\text { Film } \\
\text { Organisms }\end{array}$} \\
\hline & & & $\begin{array}{l}\text { Direct } \\
\text { Coombs }\end{array}$ & Kleihauer & \\
\hline $\begin{array}{l}\text { Abdomen } \\
\text { Heart }\end{array}$ & $\begin{array}{l}\mathbf{O} \\
\mathbf{O}\end{array}$ & $\begin{array}{l}\text { Neg } \\
\text { Pos } \\
\text { (mixed }\end{array}$ & $\begin{array}{l}\text { Neg } \\
\text { Pos } \\
g g)\end{array}$ & $\begin{array}{l}1 \% \text { foetal } \\
50 \% \text { foetal }\end{array}$ & $\stackrel{+}{0}^{+t}$ \\
\hline
\end{tabular}

Table I Haematological findings in the blood taken from the foetus at necropsy

be seen that $99 \%$ of the blood in the abdominat cavity was adult in type. It was group $O$ Rhesuse negative, direct Coombs test negative (DAGT) and therefore of donor origin. Straight films showed that it was heavily contaminated with Gram-negative diplococci. Blood from the heart showed mixed field agglutination with Rhesus anti-D sera. It was group $O$ and DAGT positive. A Kleihauer test showed that $50 \%$ of the cells were of adult type, indicating that some absorption of donor cells had taken place. No organisms were seen in the straight film.

\section{Bacteriology}

From the blood culture bottle, mother's blood culture, and blood from the abdomen of the foetus was isolated a Gram-negative coccus found to be Acinetobacter calcoaceticus (Beijerinck, 1911; Baumann, Doudoroff, and Stanier, 1968).

\section{Discussion}

Inflammation in the placenta is usually the result of direct spread of infection from the lower genital tract and is frequently associated with spontaneous premature or surgical rupture of the membranes. According to Benirschke and Driscoll (1967) there is primary leucocyte infiltration of the decidua 
capsularis, leading to chorioamnionitis and eventual involvement of the placenta itself. Maternal leucocytes infiltrate the subchorionic layer; foetal vasculitis develops and spreads to the cord. Only rarely is acute intervillous inflammation noted and in such cases signs of maternal infection are usually apparent.

Charles and Friedman (1969) state that infection complicating intrauterine transfusion follows the same pattern. In the majority of cases a mild chorioamnionitis is found and this may be associated with premature delivery. In the present case, however, the whole process seems to have been reversed as a result of infection originating within the foetal compartment. The various stages in its pathological development in the placenta bear this out; the villous capillaries stuffed with polymorphs, the formation of small micro-abscesses beneath the trophoblast layer, necrosis of this layer and eventual rupture of the villus with spread to the intervillous space, all show how the foetus eventually infected the mother.

The question then arises as to how the foetus became infected. There was certainly no evidence of aspiration pneumonia and the likeliest explanation lies with the contaminated donor blood within the foetal abdomen. There is evidence moreover that this blood was being absorbed before foetal death as $50 \%$ of the blood in the foetal heart was of donor origin. It therefore seems likely that a bacteraemia developed and the placental villous capillary network with its rich oxygen supply offered an ideal site for bacterial growth.

This is supported by the bacteriological findings as Acinetobacter calcoaceticus was isolated not only from the donor blood in the foetal abdomen, but also from the maternal circulation and the donor bottle.
From this one can only conclude that the initial site of infection was a contaminated blood transfusion bottle. If this is so one has to decide when this occurred and there are two possibilities. Contamination may have taken place during washing and packing of the red cells in order to remove the white cell layer or, alternatively, it may have occurred at the time of the intrauterine transfusion itself. In favour of the former eventuality, we found that within a week of the occurrence of the case under discussion, three other cases were reported from another hospital receiving blood processed for intrauterine transfusion from the same centre; Acinetobacter calcoaceticus was isolated from these three further cases. It is expected that a fuller report on these cases will be made elsewhere and it is not proposed to discuss them further here.

The main purpose of the report has been to draw attention to the unusual placental pathology and show how it could be related to a reversal of the normal pathway of infection.

We should like to acknowledge the cooperation we have had from our clinical colleagues.

\section{References}

Baumann, P., Doudoroff, M., and Stanier, R. Y. (1968). A study of the Moraxella Group. II. Oxidative-negative species (Genus Acinetobacter). J. Bact., 95, 1520-1541.

Beijerinck, M. W. (1911). Úber Pigmentbildung bei Essigbakterien. Zbl. Bakt., II. Abt., 29, 169-176.

Benirschke, K., and Driscoll, S. G. (1967). The Pathology of the Human Placenta. IX. Infections, p. 243. Springer, Berlin, Heidelberg, New York.

Charles, A. G., and Friedman, E. A. (1969). Rhesus Iso-Immunization and Erythroblastosis Foetalis. Butterworth, London.

Queenan, J. T. (1969). Intra-uterine transfusion. A co-operative study. Amer. J. Obstet. Gynec., 104, 397-405. 